\title{
The Archives of Internal Medicine
}

\begin{tabular}{l|l}
\hline \hline Vol. $\mathbf{X X}$ & SEPTEMBER, 1917 \\
\hline \hline
\end{tabular}

THE ETIOLOGIC AGENT OF RAT BITE DISEASE

PRELIMINARY REPORT *

J. KITAGAWA, M.D., And T. MUKOYAMA, M.D.

That there exists a particular form of disease due to rat bite has been long recognized in Japan, where incidents of rat bite have been more frequent than in certain other countries. Although some cases have been reported by American, as well as French, German, British and Spanish physicians, yet the establishment of a definite disease as a result of rat bite has been chiefly the work of Japanese observers. Miyake $^{1}$ and Crohn ${ }^{2}$ have given exhatustive reviews of the subject, together with their own case reports.

As to the etiologic agent, Ogata ${ }^{3}$ thought it to be an organism belonging to the Sporozoa, while in Cierman cases, the association of a streptothrix was reported by Schottmiiller. ${ }^{*}$ In a recent article, Blake" reports having obtained a pure culture of Streptothrix muris ratti of Schottmüller from a case of rat bite, by means of which he was able to reproduce in some rats local inflammation and proliferative lesions at the site of inoculation. The organism was nonpathogenic for guineapigs. Tileston ${ }^{6}$ adds two cases of rat bite, in the blood smears from one of which he found a streptothrix, while the second case failed to show any such organism. Recovery followed the injection of salvarsan in these cases. It may be recalled that as early as 1912, $\mathrm{Hata}^{7}$ recorded a series of cases of rat bite fever where the intravenous administration of salvarsan at the febrile stage of the disease led to a complete and permanent cure in all but two instances, in which a second injection was required during the relapses. Of special significance is the recent

* Submitted for publication Jan. 26, 1917.

* From the Pathological Institute of the Medical School of Nagoya, Japan.

* This work was done under the direction of Prof. Dr. Hayashi.

* An abstract of this paper was pullished in Japanese Feb. 12, 1916, in Chuo-Igakkai.

1. Miyake, H.: Mitt. a. d. Grenzgeb. d. Med. u. Chir., 1900, 5, 231.

2. Crohn, B. B.: The Archives Int. Med., 1915, 15, 1014.

3. Ogata: Deutsch. med. Wchnschr., 1908, 34, 1099.

4. Schottmüller, H.: Dermat. Wchnschr., 1914, 58, Supplement, 77.

5. Blake, F. G.: Jour. Exper. Med., 1916, 23, 39.

6. Tileston, W.: Jour. Am. Med. Assn., 1916, 66, 995.

7. Hata, S.: München. med. Wchnschr., 1912, 59, 854. 
discovery by Futakis and his collaborators of a spirochete in the blood, as well as in the pathologic products, of patients suffering from rat bite fever. The spirochete was pathogenic for guinea-pigs and could be transmitted from man to this animal directly. As the occurrence of a spirochete has been revealed so far only in Japanese cases, it will be of interest to add another instance where apparently the same spirochete has been isolated. Below we give a brief report of our case, together with a description of the organism found therein.

On the night of Oct. 30, 1915, the mother of one of us attempted to catch a rat by shutting it up in a room. When she seized the rat, which she supposed to be dead, the animal bit her left index finger. The lesion, which bled slightly at first, later on began to swell and cause slight local pain. When the pain grew worse. we made a slight incision at the site of injury. Although no pus appeared to be present, the swelling continued for some days. The patient's temperature, which from the first was taken daily, never exceeded normal.

On the night of November 21 , fever set in. accompanied by chills. The left axillary gland became swollen, and a large bright area of redness appeared, which extended from the onter surface of the forearm to the inner surface of the upper arm. The fever had already sulbsided by the next morning, and the red mark remained only a short time. This attack was followed by a recurrence of felrrile periods at intervals of four or five days, accompanied by severe thirst and by variously formed itching red marks on the skin which alternately appeared and disappeared. The phenomena convinced us that the casc was one of rat bite fever, and we examined preparations of the blood taken from the red marks but we failed to find any microorganism. Because of the conditions existing in the axillary lymph glands, they were extirpated during one of the febrile attacks, and inoculations were made into a monkey and several guinea-pigs and white rats. Examination of the tissues was made by dark field cultures and silver impregnations. The plasma which remained in the wound after the removal of the lymph gland and also the venous blood were removed and injected subcutaneously into guinea-pigs.

The injected monkey showed fever on the tenth day after inoculation and the guinea-pigs on the eleventh day. The febrile phenomena were almost identical with those presented by the patient, the fever returning every four or five days. We examined the lympin glands of the monkey and white rats, but nothing was found.

In January, 1916, the patient developed inflammation of the kidney. This suggested the removal of the kidney, liver, heart and spleen of the inoculated guinea-pigs, and on making smears of these (stained by Giemsa), we discovered in each organ spirochetes of a large type, such as are shown in Figures 1 and 2. The following day we examined smears of the internal organs and salivary glands of the inoculated white rats and found spirochetes of a smaller type, as shown in Figures 3 and 4 . We examined also the internal organs of the inoculated monkey, without, however, detecting any microorganisms. But examination of the internal organs of the guinea-pigs injected with blood and plasma disclosed spirochetes identical with those found in the guinea-pigs injected with portions of the lymph gland. For the sake of convenience, we will designate the spirochetes found in the guinea-pigs as Type A, and those found in the white rats as Type $B$.

That the greatest number of spirochetes was found in the lidneys of the animals is noteworthy in view of the fact that the patient was suffering from nephritis.

8. Futaki, Takaki, Taniguchi and Osumi: Jour. Exper. Med., 1916, 23, 249. 
A point of significance in connection with the mode of infection in rat bite disease is the fact that the spirochete itself was found in small numbers in the salivary glands of the rats. These spirochetes, as welt as those of Type $\Lambda$, usually show from four to eight curves. Some, however, have but from two to three curves, while others have as many as from nine to ten. As a rule, the curves of these spirochetes are regular, looser than those of the Spirochacta pallida, more sharply defined than those of $S$. refringens, and more numerous than the Weil variety (Inada). The body of our spirochete is pointed at both ends and uniformly thick in the middle. It is much shorter and thicker than S. pallida and shorter than S. refringens. Most of the spirochetes of Type $A$ are from 6 to 10 microns in length, although the smaller ones are 4 and the larger ones 12 microns long (Fig. 5). Most of the specimens of Type $B$ are shorter than those of Type $A$, that is, from 3 to 5 microns, but some are only 2 and others vary from 6 to 7 microns in length. Both types show practically the same number of spirals and also nearly the same shape, but Type B appears in general to have sharper curves and to be less pointed at the ends, but some specimens closely resemble Type $\Lambda$. Nevertheless, the spirochete of Type B has always a smaller body than that of Type $A$ and it is not difficult to recognize to which type a given specimen belongs.

More investigations will be necessary in order to determine definitely whether these spirochetes which show such differences with respect to size constitute one or two groups. It is a question whether these differences in size do not rather proceed from the differences of the inoculated animals or of the varying period of development of the spirochetes, as occurs in the case of bacteria and parasites. For further investigation of this question, we injected ordinary guinea-pigs and white rats with the spirochete-containing organs of the inoculated guinea-pigs, some of which had been subjected to Roentgen-ray treatment after undergoing preliminary splenectomy.

On examining the internal organs of all the white rats and guineapigs, we found not only that the spirochetes appeared in greater numbers in the animals that had undergone splenectomy than they did in the animals not so treated, but that they had become more pointed at the ends and had acquired looser curves. On the whole, Type B appeared to have somewhat approximated Type A.

The last examination showed the interesting phenomenon of two spirochetes of Type B having become so closely connected that they appeared to be one specimen in the process of undergoing division. Some seemed to be on the point of separating and remained connected only by means of very fine colorless threads; others apparently had 
become quite detached from one another. Two spirochetes thus connected usually occupied a continuous line, but in some cases they formed an angle. Each of them was invariably small, from 2 to 3, or, in rare instances, 4 microns long; consequently, the number of spirals was also small. The specimens had usually from two to four and sometimes five spirals. It looked as if those specimens that possessed numerous spirals had been divided into two (Figs. 6, 7 and 8).

It was always quite uncertain in which of the internal organs the above-mentioned spirochetes were most frequently found. The fact that our patient had an unmistakable nephritis, and that after temporary recovery, there was a relapse, this attack being accompanied by enlargement of the liver, added to the fact that another patient of ours had had an attack of rat bite disease attended by cardiac paralysis, strongly suggests to us that every internal organ of man is subject to invasion by this spirochete, just as was the case with the experimental animals, no real differentiation between the pathologic processes in man and in the experimental animals being distinguished.

In our staining, in addition to the old and new Giemsa stain and Prof. Matsuura's modification of Leviditi's silver impregnation method, we successfully employed red-methyl-brown, a Giemsa-like fluid now being perfected by Segawa; also azulin, fuchsin, methyl-brown, gentian violet, etc. None of these methods disclosed any great difference between Types $\Lambda$ and $B$.

We carried on control tests in ten healthy guinea-pigs, ten white rats and six house rats. In a kidney preparation of one of the house rats we discovered only one typical spirochete of Type $B$. In the salivary glands of one of the white rats and in one house rat we found spirochetes more than 20 microns in length. These spirochetes possessed regular curves and resembled $S$. refringens.

We now wish to consider whether our spirochete is really identical with the etiologic agent of rat bite fever.

It must first of all be stated that the disease is characterized by repeated attacks. There are two kinds of discases caused by protozoa, those in the first class run a swift course, such as relapsing fever and malaria, those of the second group assume a chronic form which in some cases is very extreme; they are characterized by a recurrence of attacks during several subsequent years. According to Prof. Kusunoki, one or two yearly relapses occur for ten years after recovery from rat bite disease. Recently we saw a patient who still suffered recurrences fifteen years after the first attack of the disease. The fact that these attacks recur for as long as ten years appears to prove conclusively that the immunity against the agent is incomplete, and this leads us to 


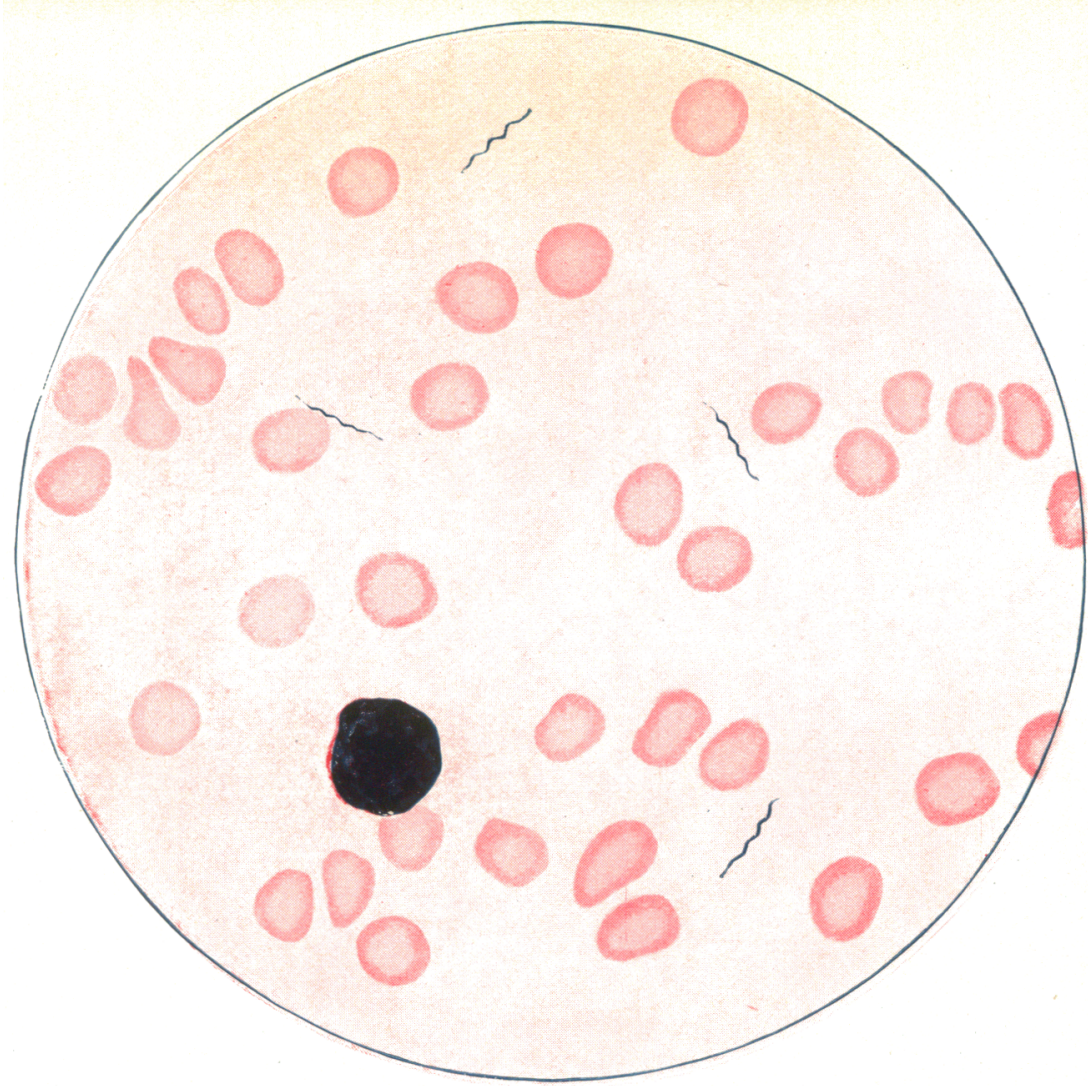

Fig. 1.-Giemsa-stained smear of kidney of guinea-pig inoculated with axillary gland of patient (Spirochete of Type A).

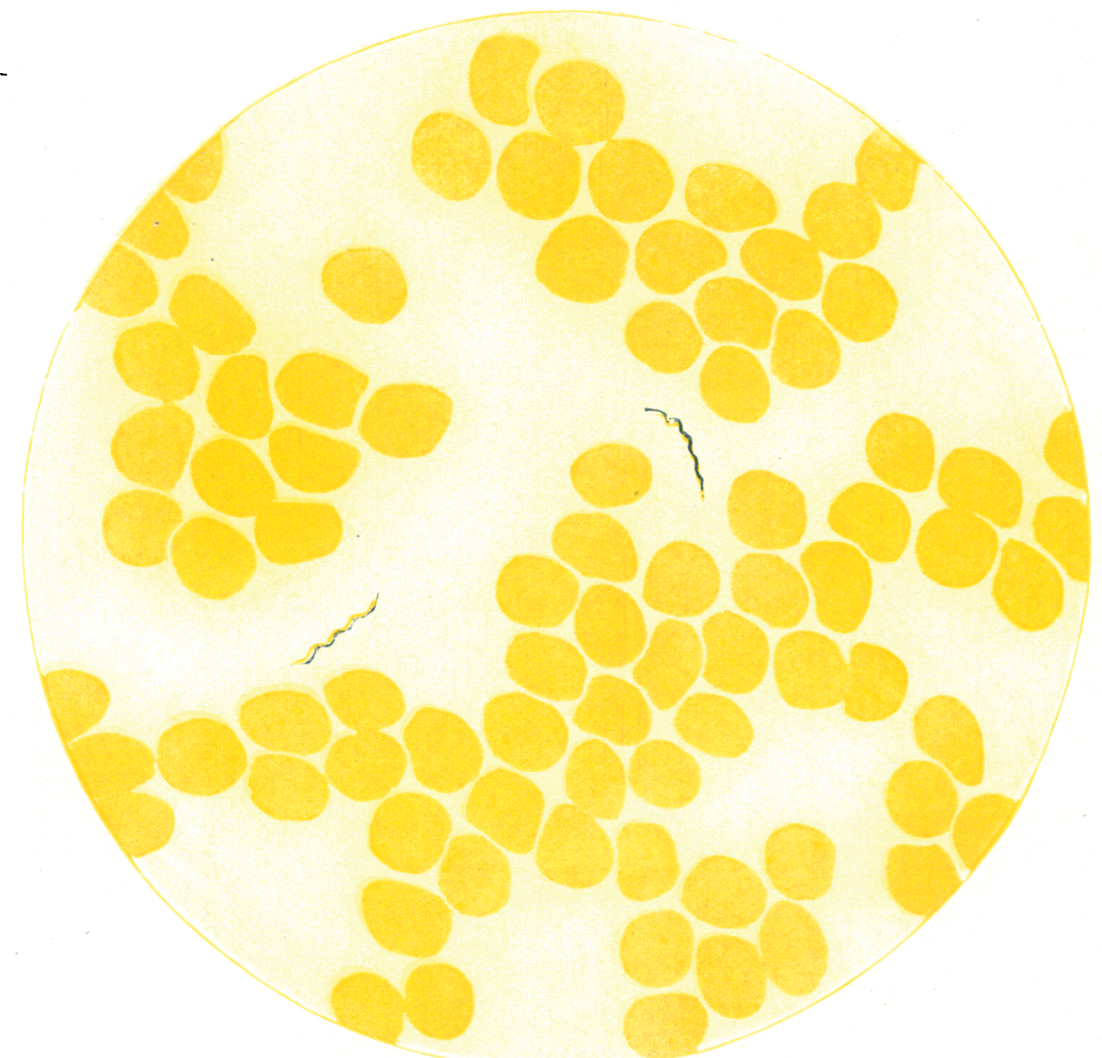

Fig. 2.-Silver impregnation of heart's blood of the same guinea-pig (Spiro. chete of Type A).

Downloaded From: http://archinte.jamanetwork.com/ by a University of California - San Diego User on 06/05/2015 


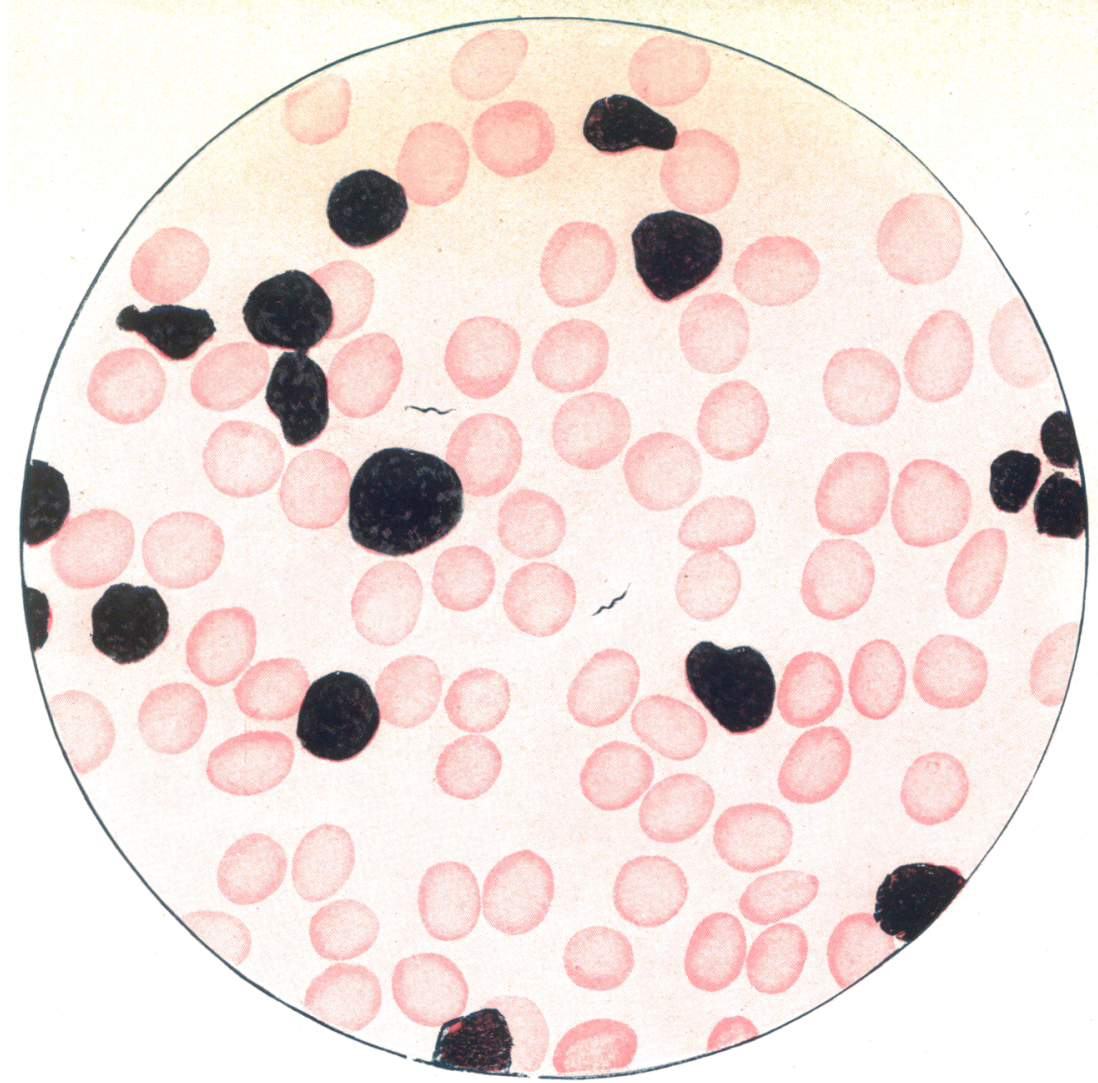

Fig. 3.-Giemsa-stained smear of kidney of white rat inoculated with patient's axillary gland (Type B).

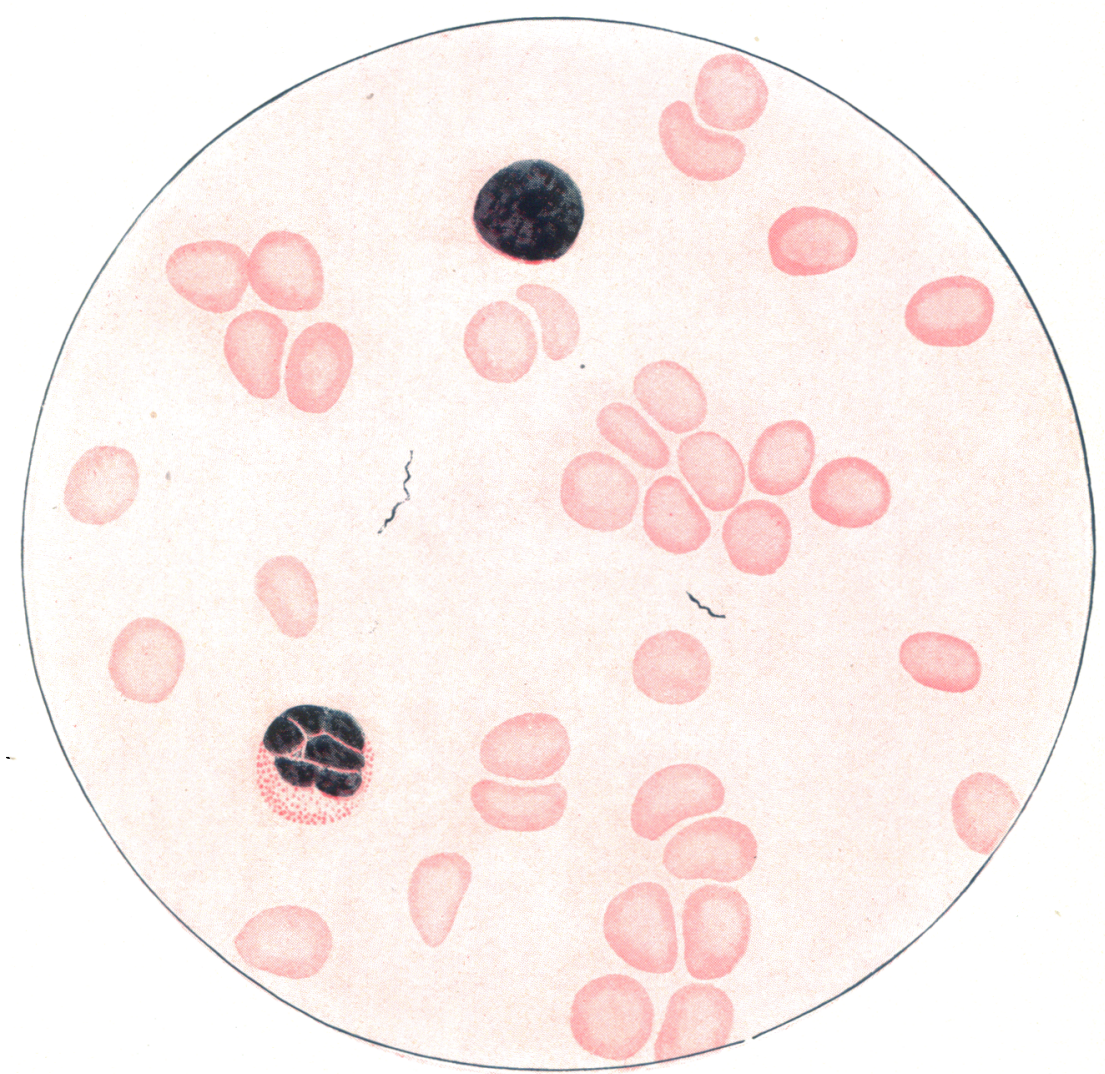

Fig. 4.-Giemsa-stained smear of liver of same white rat (Type B). Downloaded From: http://archinte.jamanetwork.com/ by a University of California - San Diego User on 06/05/2015 


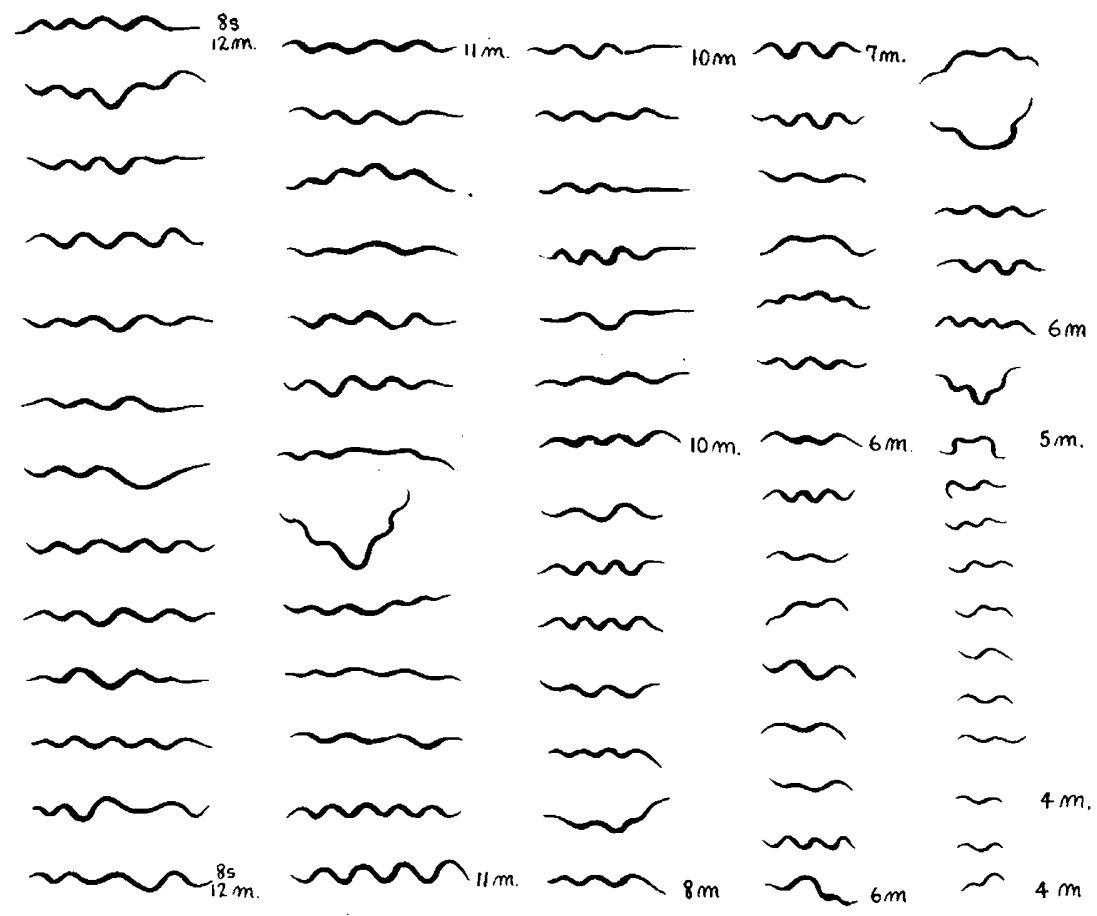

Fig. 5.-Principal forms of spirochetes of Type A found in the organs of the inoculated guinea-pig; $s$, spiral; $m$, micron.

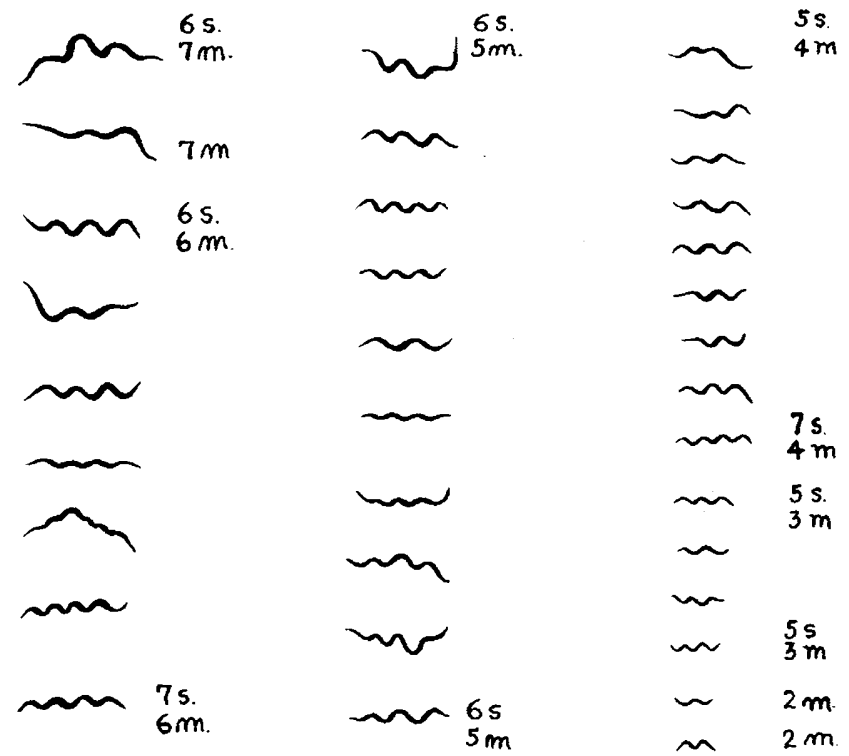

Fig. 6.-Principal forms of spirochetes of Type B found in the organs of the inoculated white rat; $s$, spiral; $m$, micron. 


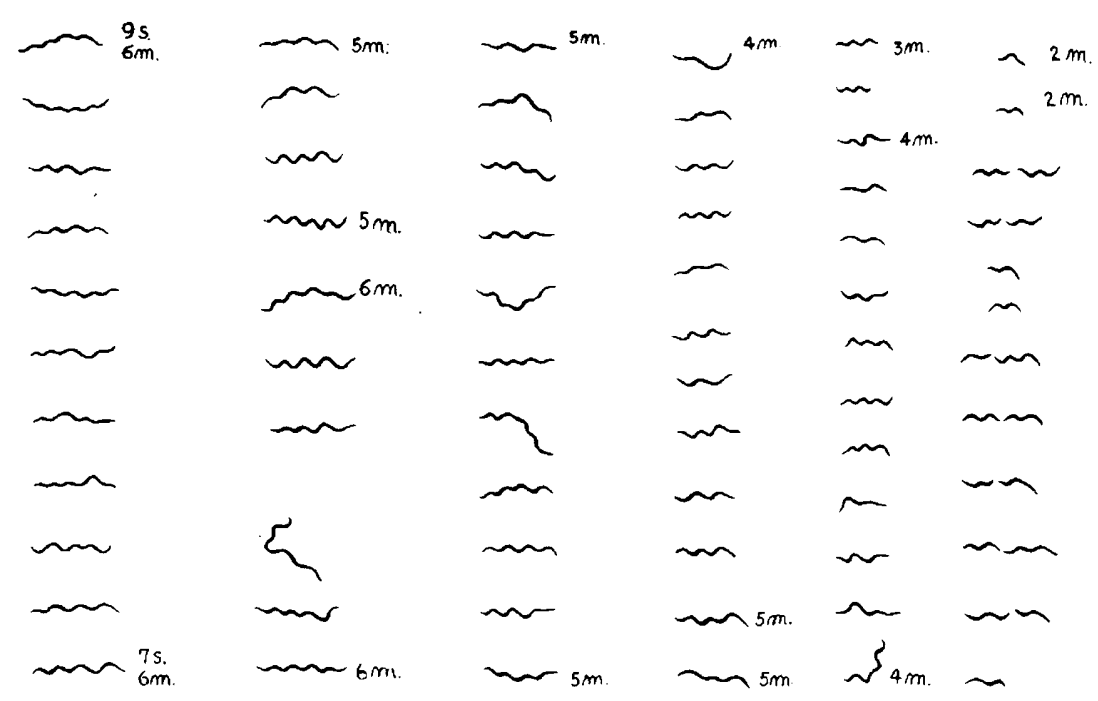

Fig. 7.-Spirochetes of Type B, obtained by inoculation of the splenectomized white rat (after previous subjection to Roentgen-ray treatment) with portions of the organs of another white rat containing spirochetes of Type B; $s$, spiral; $m$, micron.
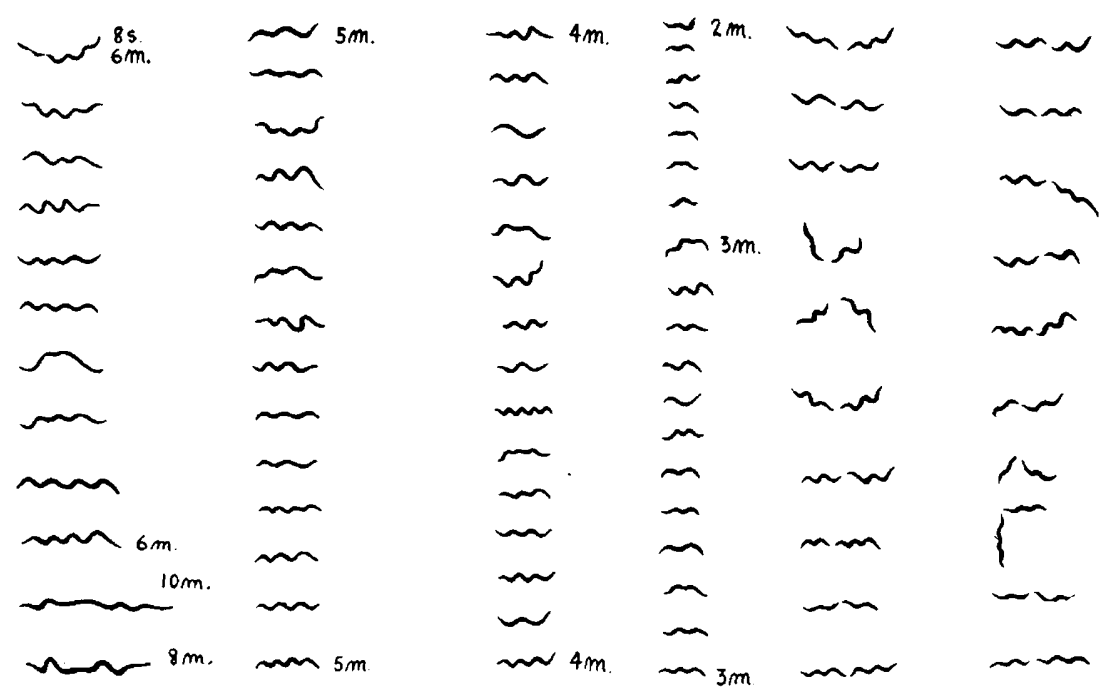

Fig. 8.-Varieties of form of spirochetes of Type B, obtained by inoculation of the splenectomized guinea-pig with the same organs as in Figure 4, 2, after previous subjection to Roentgen-ray treatment; $s$, spiral; $m$, micron. 
conclude that the agent belongs to the group of protozoa that undergo gradual but marked modification with regard to form and toxicity. Moreover, since there is a definite period of incubation, followed by an eruption and swelling of the lymph glands, and since arsenic, especially salvarsan, is very efficacious in the treatment of the disease, our opinion is confirmed that we are dealing with a protozoan of the spirochetal variety.

The literature on the Wassermann reaction states that the reaction is positive in the case of such spirochetal diseases as relapsing fever, malaria, frambesia tropica and oriental sore. Dr. Kusunoki's experiments with this reaction, however, in five cases of rat bite fever showed it to be negative in four cases and positive in but one. It is possible, of course, that the latter subject had contracted a syphilitic infection at some time in the past. According to personal information received from Dr. Inada, the Wassermann reaction was negative in each of three cases of Weil's disease. It seems, therefore, that in rat bite disease and in some other spirochetal diseases we cannot place any reliance on the Wassermann reaction.

Repeated testing of the Wassermann reaction in one patient produced negative results. We therefore made an alcohol extract of the liver and heart of guinea-pigs harboring spirochetes of Type A, with which we made complement fixation tests. The complement fixation test was carried out twice in the case of a patient afflicted with rat bite fever with positive results. We applied the Wassermann reaction which also was positive. Subsequently, in order to prove whether or not our spirochetal antigen possessed any special peculiarity, we undertook experiments in complement fixation on patients suffering from rectal cancer, syphilis, and other similar diseases, at the same time applying the Wassermann test. The results of these experiments are given in the accompanying table.

Results of Experiments in Complement Fixation

\begin{tabular}{|c|c|c|c|c|c|}
\hline Patient & Disease & $\begin{array}{c}\text { Wassermann } \\
\text { Reaction }\end{array}$ & Control & $\begin{array}{l}\text { Reaction } \\
\text { Spiro. } \\
\text { Antigen }\end{array}$ & Control \\
\hline 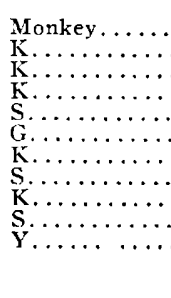 & $\begin{array}{c}\text { R. b. disease } \\
\text { R. b. disease } \\
\text { R. b. disease } \\
\text { R. b. disease } \\
\text { Rectal cancer } \\
\text { Syphilise } \\
\text { Syphilis } \\
\text { Syphilis } \\
\text { Syphilis } \\
\text { Syphilis } \\
\text { Parenchyma. } \\
\text { tous kerati. } \\
\text { tis }\end{array}$ & $\begin{array}{l} \pm \\
\pm \\
\pm \\
\pm \\
\pm+ \\
\pm\end{array}$ & $\begin{array}{l} \pm \\
= \\
= \\
= \\
=\end{array}$ & $\begin{array}{l} \pm \\
\pm \\
= \\
=\end{array}$ & $\begin{array}{l}= \\
= \\
= \\
=\end{array}$ \\
\hline
\end{tabular}


It will be noticed that the reaction to the antigen of the spirochete of Type A proved positive in one case of rat bite disease.

Our organism of Type A not only possesses more spirals than does the spirochete discovered by Dr. Futaki in preparations stained with India ink but its curves are also much more regular. In comparison with those discovered by Dr. Futaki, the majority of our spirochetes, which are found in great quantities in our preparations, appear to belong to a different species. Yet they are nearly of the same size; moreover, irregularly shaped spirochetes, having fewer curves, were occasionally found in our preparations, so we at first concluded that Type A was of the same species as Dr. Futaki's spirochete. But another preparation of the variety discovered by Dr. Futaki, stained by the silver impregnation method of Levaditi, which had been found in the lymph gland of a patient, was exhibited at a meeting of the Pathological Society of Tokio, and from this specimen we were able to determine that these spirochetes were different from Type A. The organisms of Type B, however, seem to be identical with Dr. Futaki's specimen and also with those discovered at the same time by $\mathrm{Dr}$. Ishiwara.

\section{SUMMARY}

The two types of spirochetes, found in the guinea-pigs and rat, respectively, not only varied considerably with respect to size, but also showed differences with regard to the distinctness of the spirals and the pointedness of the ends, which facts seem to us to indicate that these spirochetes belong to two different species. Yet, since the staining brought out no definite distinctions between them, and as they showed practically the same number of curves, it appears possible that the above-mentioned difference of form was a result of the differences existing between the inoculated animals, or that the spirochetes may have been in different stages of development. At all events, it is interesting to note that the spirochetes obtained from inoculation with the lymph gland and the lymph plasma derived from the same patient also appear to be of different sizes. Whether Type $A$ and Type $B$ are really identical, or, if they are not, which one is the etiologic agent, are points which cannot be determined without further investigation. 